\title{
BIOGRAFIAS ENTRELAÇADAS: UMA FAMÍLIA DE AFRODESCENDENTES EM PORTO ALEGRE NO PÓS-ABOLIÇÃO
}

- MARIA ANGÉLICA ZUBARAN

Universidade Luterana do Brasil (ULBRA)

\section{VITOR DA SILVA COSTA}

Universidade do Vale do Rio dos Sinos

Neste trabalho, analisam-se as biografias dos membros de uma família afrodescendente, os Baptista da Silva, no pós-abolição, no Rio Grande do Sul. Busca-se investigar a trajetória de vida de cada um de seus membros, do pai Major João Baptista da Silva (1858-1937) e de seus dois filhos, Felippe Baptista da Silva (1883-1923) e João Baptista da Silva Junior (1891-1920), na sociedade porto-alegrense da época. O objetivo da análise é mapear os mecanismos de inserção social desses sujeitos negros na sociedade porto-alegrense e problematizar estereótipos e preconceitos raciais atribuídos aos negros nesta época, particularmente, a imagem de anomia social das famílias negras. Inicialmente, discutem-se estudos realizados sobre biografias, nos âmbitos internacional, nacional e regional, e também a historiografia brasileira recente sobre famílias de afrodescendentes. Em termos teórico-metodológicos, trata-se de uma pesquisa documental, fundamentada teoricamente nos estudos sobre biografias, em particular, de biografias de afrodescendentes, cruzando-se várias fontes de pesquisa: os jornais O Exemplo e A Federação, Livros de Registro de óbitos, Termos de Juramento de Irmãos da Santa Casa de Misericórdia de Porto Alegre, além de Registros da Cúria Metropolitana. A pesquisa demonstra o envolvimento dos membros da família Baptista da Silva no jornal de imprensa negra 0 Exemplo, em irmandades negras e sociedades recreativas e culturais. Os fragmentos biográficos revelam também que estabelecer laços familiares, trabalhar regularmente e educar-se eram estratégias de inclusão social que faziam parte da trajetória de vida dos afro-rio-grandenses, em Porto Alegre/RS no pós-abolição.

Palavras-chave: Educação. Biografias. Famílias Negras. 


\section{FAMILY IN POST-ABOLITION PORTO ALEGRE}

This work analyzes the biographies of the members of an Afro-descendant family, The Baptista da Silva, in the post-abolition, in Rio Grande do Sul. The objective is to investigate the life trajectory of each one of its members, the father Major João Baptista da Silva (1858-1937) and his two sons, Felippe Baptista da Silva (1883-1923) and João Baptista da Silva Junior (1891-1920), in Porto Alegre society at the time. The objective of the analysis is to map the mechanisms of social insertion of these black subjects in the Porto Alegre society and to problematize stereotypes and racial prejudices attributed to blacks in this era, particularly the image of social anomie of black families. Initially, we discuss studies on biographies at the international, national and regional levels, as well as the recent Brazilian historiography on families of Afro-descendants. In theoretical-methodological terms, this is a documentary research, based theoretically on studies on biographies, in particular, biographies of Afro-descendants, crossing several sources of research: the newspapers $O$ Exemplo e A Federação, Death Register Books, Oath Terms of Brothers of the Holy House of Mercy of Porto Alegre, and Registers of the Metropolitan Curia. The research demonstrates the involvement of members of the Baptista da Silva family in the black press newspaper 0 Exemplo, in black brotherhoods and cultural and recreational societies. Biographical fragments also reveal that establishing family ties, working regularly and educating themselves were strategies of social inclusion that were part of the life trajectory of Afro-Rio Grande do Sul in Porto Alegre / RS in the post-abolition era.

Keywords: Education. Biographies. Black Families.

\section{AFRODESCENDENTES EN PORTO ALEGRE EN EL POST- ABOLICIÓN}

En este trabajo se analizan las biografias de los miembros de una familia afrodescendiente, los Baptista da Silva, en Rio Grande do Sul, en el post-abolición. Se busca investigar la trayectoria de vida de cada uno de sus miembros, del padre Major João Baptista (1858-1937) y de sus dos hijos, Felippe Baptista da Silva (1883-1923) y João Baptista da Silva Junior (1891-1920), en la sociedad porto-alegrense de la época. El objetivo del análisis es mapear los mecanismos de inserción social de esos sujetos negros en la sociedad porto-alegrense y problematizar estereotipos y preconceptos raciales atribuidos a los 
negros en esta época, particularmente, la imagen de anomia social de las familias negras. Inicialmente, se discuten estudios realizados sobre biografias en los ámbitos internacional, nacional y regional y también la historiografia brasileña reciente sobre familias de afrodescendientes. En términos teórico-metodológicos, se trata de una investigación documental, fundamentada teóricamente en los estudios sobre biografias, en particular, de biografias de afrodescendientes, cruzando varias fuentes de investigación: los periódicos $O$ Exemplo y A Federação, Libros de Registro de muertes, Términos de Juramento de Hermanos de la Santa Casa de Misericordia de Porto Alegre, además de Registros de la Curia Metropolitana. La investigación demuestra, la participación de los miembros de la familia Baptista da Silva en el periódico de prensa negra El Ejemplo, en hermandades negras y sociedades recreativas y culturales. Los fragmentos biográficos revelan también que establecer lazos familiares, trabajar regularmente y educarse eran estrategias de inclusión social que formaban parte de la trayectoria de vida de los afro-río-grandenses en Porto Alegre/RS en la post-abolición.

Palabras clave: Educación. Biografias. Familias Negras.

\section{Introdução}

Neste estudo, pretende-se analisar a trajetória dos membros de uma família negra, os Baptista da Silva, no pós-abolição, discutindo e problematizando a importância dos laços familiares, da educação, das associações e clubes negros e da imprensa negra para a inserção social dos negros no pós-abolição. Dessa forma, no lugar de representar os afro-brasileiros como sujeitos homogêneos e a-históricos, pretendese investigar suas trajetórias particulares, enquanto sujeitos com diversas articulações sociais, religiosas e culturais. 0 recorte temporal estende-se do início do século XIX até o século XXI, com o bisneto Claudio Baptista de Souza.

As primeiras referências aos membros da família Baptista da Silva foram encontradas no jornal de imprensa negra O Exemplo (18921930), primeiro periódico escrito por negros e

1 Cláudio Batista de Souza, bisneto do major João Baptista da Silva é Defensor Público aposentado. para negros em Porto Alegre, quando se investigavam as lideranças negras que participavam deste jornal. Passamos então a pesquisar a trajetória desses sujeitos negros, no pós-abolição, suas redes de sociabilidade e suas estratégias de inserção social na sociedade da época.

Neste sentido, pretende-se neste trabalho problematizar estereótipos e preconceitos raciais sobre os negros no pós-abolição, particularmente, as ideias de anomia social e de incapacidade intelectual dos afrodescendentes, salientando-se a atuação dos membros da Família Baptista da Silva na imprensa negra, particularmente no jornal $O$ Exemplo e irmandades religiosas, além de seus percursos como funcionários públicos e na educação.

Pretende-se, ainda, salientar a importância dos laços familiares como estratégia de inserção social e cultural de afrodescendentes no 
período pós-abolição, particularmente, nas primeiras décadas do século XX. Durante muito tempo, a história da família no Brasil praticamente ignorou o tema da família e das relações familiares entre a população afrodescendente. De acordo com Salles e Soares (2005), o olhar branco dos observadores raramente conseguiu captar o lar negro, levando muitos historiadores a afirmar que a vigência do tráfico africano, a violência e a ausência formal de direitos inerentes à escravidão tornaram impossivel a constituição de relações familiares no cativeiro (SALLES; SOARES, 2005, p. 49). Como apontam Salles e Soares, a nova história da família prioriza o estudo das famílias afrodescendentes, suas relações familiares, valores e visões do mundo.

A abordagem teórico-metodológica desse estudo fundamenta-se nas novas tendências das pesquisas biográficas, tanto em autores internacionais, como François Dosse (2009) e Sabina Loriga (2011), como em autores nacionais, como Benito Schmidt (2000) e Petrônio Domingues (2009), e também em estudos sobre as trajetórias de afrodescendentes no Rio Grande do Sul, destacando-se os trabalhos de Liane Susan Müller (2013), José Antônio dos Santos (2008; 2011), Beatriz Loner (2012), Paulo Moreira (2011) e Maria Angélica Zubaran (2016).

O historiador francês François Dosse (2009), na obra Desafio Biográfico - Escrever uma vida, aponta que a biografia nasce de uma mescla entre pesquisa histórica e romance literário. Para o autor, "o gênero biográfico é uma mescla de erudição, criatividade literária e intuição psicológica" (DOSSE, 2009, p. 60). Neste sentido, Dosse argumenta que o historiador biógrafo deve se valer de indícios e detalhes, que podem parecer insignificantes, mas que são representativos para reconstruir a trajetória de um sujeito, considerado dentro de um contexto maior.
Sabina Loriga (2011), na obra O pequeno $x$ : da biografia à história, salienta que o uso do termo "biografia" surgiu a partir do século XVII, com os ingleses Izaak Walton e John Aubrey. Loriga propõe que o indivíduo, objeto da biografia, é complexo, marcado por ambiguidades e contradições. A autora interpreta a biografia como a apreensão da densidade social de uma vida que é dinâmica e diversa. A autora defende que a biografia dever ser explorada em toda a sua heterogeneidade e não como um gênero padronizado:

Por isso, em vez de formular regras gerais sobre um gênero de escritura particularmente volúvel, parece-me mais fecundo meditar sobre essa fronteira fluida que separa a biografia da história e da literatura, e analisar as proibições, os abalos, as incursões recíprocas que a transpõem [...]. (LORIGA, 2011, p. 19)

De acordo com Loriga (2011), a retomada do método biográfico como recurso acadêmico fez-se no período de contestação aos modelos de interpretação marxista e estruturalista e resultou no deslocamento das análises do coletivo, para as análises do individual e subjetivo. A chamada crise dos paradigmas gestou a volta da biografia como campo de possibilidades do pesquisador. A biografia foi sendo ressignificada e democratizada. Segundo a autora, "[...] a aposta hoje não é mais no grande homem, mas no homem qualquer" (LORIGA, 2011, p. 213). A biografia do homem qualquer abriu novo campo de possibilidades ao historiador, antes restrito à escrita de vida de sujeitos renomados e vitoriosos, mostrando que toda a trajetória de vida é importante.

No âmbito nacional, Petrônio Domingues (2009) argumenta que os relatos biográficos possibilitam relativizar a linearidade das trajetórias dos afrodescendentes, revelando que apesar de inúmeras dificuldades, intelectuais negros conseguiram se destacar e alcançar prestígio social no mundo dominado pelos 
brancos. 0 autor propõe por meio de biografias problematizar e desconstruir essas narrativas generalizantes, esquemáticas e reducionistas, e visibilizar outros modos de ser negro(a) no pós-abolição.

Em recente estudo, Benito Bisso Schmidt afirma que "na historiografia contemporânea as biografias servem justamente como via de investigação dos espaços de liberdade possiveis aos agentes sociais em diferentes contextos" (2013, p. 68). Em outro estudo, o autor destaca ainda, a importância de se analisar pessoas comuns, que não figuraram em grandes feitos ou fatos históricos, mas cuja vida cotidiana faz parte do contexto social, político e cultural, de uma época. 0 autor seleciona o cotidiano como foco principal de seu estudo e enfatiza a importância de analisar-se o cotidiano do sujeito inserindo-o no contexto histórico e social da época (SCHMIDT, 2000, p. 23).

Neste sentido, o estudo das biografias entrelaçadas de uma família afrodescendente permite melhor compreender os laços sociais construídos e os caminhos de inserção social que foram trilhados no pós-abolição, demonstrando que apesar das inúmeras dificuldades de inserção social em uma sociedade racista, alguns afrodescendentes lograram ascender socialmente e ocupar lugares de destaque no pós-abolição.

No Rio Grande do Sul, Paulo Roberto Staudt Moreira (2011) investigou a trajetória de Aurélio Viríssimo de Bittencourt (1849-1919), que ganhou destaque na carreira pública em Porto Alegre, chegando a ocupar o cargo de secretário do então presidente Júlio de Castilhos. Aurélio Viríssimo de Bittencourt foi também provedor da Santa Casa de Misericórdia e irmão venerável da Ordem Terceira de Nossa Senhora das Dores, mostrando-se muito ativo nas irmandades religiosas da capital gaúcha (MOREIRA, 2011). De acordo com o autor, a principal estratégia utilizada para afirmar-se na sociedade da época foi sua associação à figura de Júlio de Castilhos, evidenciada na troca de correspondência entre ambos, discutindo assuntos políticos e administrativos, além de questões particulares. ${ }^{2}$

José Antônio dos Santos (2011) também investigou a trajetória de intelectuais afrodescendentes no pós-abolição, a partir da imprensa negra gaúcha, em específico no jornal O Exemplo. 0 autor destaca a construção de escolas étnicas, clubes sociais de cunho recreativo e beneficente, que tinham como objetivo, além do lazer, promover uma consciência étnica, contemplando políticas e estratégias para fortalecer o grupo.

Beatriz Ana Loner (2012) estudou as trajetórias de três afrodescendentes no pós-abolição, destacando a educação, as redes sociais e o associativismo étnico. Mais recentemente, Maria Angélica Zubaran (2016) analisou fragmentos biográficos de afrodescendentes que conquistaram diplomas superiores e cujas trajetórias foram destaque no jornal $O$ Exemplo, como modelos de negros com os quais a comunidade negra poderia se identificar e tecer laços de pertencimento no pós-abolição.

Para fins desse estudo, vale também discutir-se brevemente a historiografia brasileira recente sobre famílias afrodescendentes. Ana Lugão Rios (1990), em sua dissertação de mestrado, Família e Transição: Famílias Negras em Paraíba do Sul (1872-1920), salientou a permanência dos laços familiares de libertos após a abolição. Tomando como base os registros civis e paroquiais de Paraíba do Sul, demonstrou a existência de famílias negras no pós-abolição. Porém, a falta de informações nos registros referentes a cor impediu que a autora acompanhasse o desenvolvimento dessas famílias, limitando-se à primeira década do pós-abolição. O trabalho de Ana Lugão Rios e os dados compilados pela autora abriram um campo de

2 Ver mais em: Velho (2013). 
pesquisa e de estudo que até então pouco valorizado, imprimindo novas abordagens acerca do tema.

Manolo Florentino e José Roberto Góes (1997), na obra A Paz das Senzalas: Famílias escravas e tráfico atlântico, Rio de Janeiro, c. 1790 - c.1850, destacaram o papel da família como forma de resistência e de fortalecimento das identidades dos sujeitos negros. Os autores utilizaram o conceito de "transmissões geracionais de padrões culturais", importante também neste estudo, para argumentar que os ensinamentos passados ao longo das gerações sobreviviam às separações por vendas. Esses referenciais culturais podem ser evidenciados no caso da família Baptista da Silva, em que os filhos assimilaram os ensinamentos transmitidos pelo pai e se apropriaram desses ensinamentos na construção de suas identidades.

Hebe de Mattos também dedicou parte de seus trabalhos aos estudos sobre família escrava e liberta, particularmente na obra Das cores do silêncio: os significados da liberdade no Sudeste escravista, Brasil Século XIX, resultado de sua tese de doutorado, publicada em 1995 pelo Arquivo Nacional e reeditada em 1998. No capítulo Laços de Família, a autora problematiza o argumento da incapacidade do negro em formar família no cativeiro e de que só era possivel se espelhar no modelo patriarcal branco. Ela chama a atenção para as relações de amasiamento que resultavam em divergências nos registros civis, o que poderia ocorrer tanto nas relações familiares de senhores como na de escravos (MATTOS, 1998). Neste sentido, entender as relações pessoais e a mobilidade espacial são essenciais para a compreensão do contexto que a família escrava e liberta estava inserida na zona rural. De acordo com a autora:

Fixar-se numa região significava estabelecer laços. O casamento ou mesmo a relação consensual com uma 'caseira' significava estabelecer relações com uma família da região. Empregarse como camareira ou jornaleiro era colocar-se provisoriamente sob a proteção de um sitiante ou fazendeiro, mas constituir família retirava o sentido de provisoriedade daquela situação e abria as portas para o acesso à roça de subsistência. O casamento e a formação de uma família nuclear estável, ou outras formas de associação de caráter familiar tornavam-se assim; pré-condição para a produção independente. (MATTOS, 1998, p. 58)

Mattos problematiza a ideia de que as famílias escravas eram desorganizadas e promíscuas, em relação a um modelo familiar branco. A autora destaca semelhanças entre os dois grupos raciais, particularmente no que diz respeito às tensões desses arranjos familiares (MATTOS, 1998). Já Sheila de Castro Faria (1998), no livro "A Colônia em movimento: Fortuna e Família o cotidiano Colonial", analisa as relações familiares no período Colonial na Paraíba do Sul, em Campo dos Goitacazes. A autora salienta as táticas de sobrevivência empregadas pelos cativos, fosse por meio das relações de compadrio, da compra de terras, do casamento legal ou da formação de uma família. Para realizar a pesquisa sobre a família escrava, Faria utilizou-se de fontes paroquiais, principalmente de inventários e testamentos, buscando entender as relações econômicas e a mobilidade dos cativos em diálogo com os senhores. Nas palavras da autora:

Tecendo um paralelo, presumo que escravos com família tivessem mais problemas ou menos intenção de se deslocar do que outros, solteiros e sem filhos. Os laços familiares tendiam a estabilizar o indivíduo, e com isso contavam os senhores, ao reconhecer, socialmente, por meio de casamento legal, casais escravos. Dificultar-lhes as fugas, adequá-los ao cativeiro e ao trabalho, estabilizá-los na região e torná-los dóceis foram objetivos ferrenhamente perseguidos por senhores. (FARIA, 1998, p. 327)

Já Robert Slenes, em 1999, publicou o livro “Na Senzala Uma Flor: Esperanças e recorda- 
ções na formação da família escrava - Brasil Sudeste, século XIX", utilizando-se dos relatos de viajantes do século XIX para analisar as relações familiares escravas. 0 autor problematiza as visões sobre famílias negras de viajantes europeus como: J. J. Von Tschudi, Luis Couty, Johann Moritz Rugendas e Jean Baptiste Debret, que viam o negro e seus arranjos familiares como "incivilizados" e fora dos padrões morais. $\mathrm{O}$ autor pontua que a estabilidade da família escrava era aceitável apenas quando possibilitaria a valorização do patrimônio do senhor. "[...] A luta para assegurar o bem-estar da família tornava-se também uma luta para aumentar o patrimônio, mas a partir desse momento inicial, a propriedade e a família marcham juntas, de mãos dadas, uma reforçando a outra" (SLENES, 1999, p. 140). 0 autor salienta que entender a organização de famílias negras através do olhar branco do século XIX contribui para percebermos as ideias preconceituosas sobre a cultura negra que se estenderam do pós-abolição até a contemporaneidade.

No ano de 2010, Francisco Vidal Luna e Herbert S. Klein lançaram o livro "Escravismo no Brasil", onde destacam aspectos sociais e econômicos da escravidão no Brasil. Na segunda parte do livro, os autores analisam o papel da família:

No cerne da nova cultura negra estava a unidade familiar. Embora os senhores experimentassem todos os tipos de organização comunitária para os escravos de suas fazendas, a maioria dos cativos viveu em unidades familiares. (LUNA; KLEIN, 2010, p. 237)

Segundo Luna e Klein (2010), a formação da família negra parece ter significado a construção de uma rede de recursos sociais e culturais amplos, que contribuiu, de diversas formas, para a sobrevivência econômica e psicológica dos afrodescendentes no pós-abolição. Os autores sustentam que a maioria dos escravos buscava estabelecer relações com pessoas li- vre ou forras, com o objetivo de facilitar seu trânsito social no meio que estavam inseridos.

Assim, o casamento entre indivíduos de diferentes condições sociais era uma estratégia de inserção social que facilitava a aceitação social na comunidade. Da mesma forma, os autores sublinham que a condição da família escrava estava relacionada à condição do senhor. Os donos de escravos que possuíam um plantel menor de cativos poderiam facilitar aos seus escravos viverem em família com menor probabilidade de serem separadas por venda (LUNA; KLEIN, 2010). Os autores finalizam sua investigação destacando que pouco se sabe ainda sobre as condições de moradias das famílias escravas e detalhes sobre suas relações de parentesco.

Também Rodrigo de Azevedo Weimer (2013), na tese de doutorado intitulada $A$ gente da Felisberta: consciência histórica, história e memória de uma família negra no litoral riograndense no pós-emancipação, produziu uma análise geracional de uma família da região de Morro Alto no Rio Grande do Sul, por meio de entrevistas com descendentes da família de Felisberta, conseguindo dar segmento aos estudos de Rios (1990), ao acompanhar a trajetória de um grupo familiar, e perceber suas transformações. Para isso, o autor salienta que buscou:

[...] dividir a 'gente da Felisberta', grosso modo, em quatro gerações: 'geração de escravos', 'geração de camponeses', 'geração de migrantes' e 'geração de quilombolas'. Através delas pretendo expressar aqueles que passaram pela experiência do cativeiro, estabelecimento de um campesinato negro na região de Morro Alto, movimentações populacionais de meados do século XX e a contemporânea emergência de etnicidades entre os descendentes daqueles cativos. (WEIMER, 2013, p. 29)

Nesse aspecto, as memórias orais foram fator determinante para que o autor pudesse conectar as gerações do grupo familiar, permitin- 
do mapear continuidades e rupturas descendentes. Para o presente trabalho, as memórias orais do senhor Claudio Batista de Souza, bisneto do major João Baptista da Silva, foram fundamentais para a reconstrução da árvore genealógica da família Baptista da Silva.

Por último, destaca-se também o trabaIho de Terence Burchert Miranda (2013), que apresentou a monografia intitulada Mobilidade e trabalho: Trajetórias de famílias negras de Biguaçu na primeira metade do século $X X$, na Universidade Federal de Santa Catarina. A autora utilizou entrevistas orais para melhor compreender a relação das memórias com o passado escravo e a manutenção da tradição familiar. A pesquisa centrou-se na análise de quatro famílias que migraram de áreas rurais de Biguaçu para zonas urbanas desse município e de Florianópolis, entre 1930 e 1940. Na análise contextual e histórica do negro, a autora aponta a família como um mecanismo que possibilitava garantir estabilidade e resistir à escravidão e que no pós-abolição continuou desempenhando um elo de fortalecimento identitário e social:

A história dos negros no pós-abolição envolveu, em muitos casos, deslocamentos espaciais, continuidades e mudanças e a inserção em novos ambientes sociais, e essas situações implicaram na elaboração de novos mecanismos de socialização. A família, nesse contexto, pode ter permanecido como um meio aglutinador, fortalecendo-os e possibilitando o protagonismo na condução de suas vidas. (MIRANDA, 2013, p. 19)

Miranda mapeia famílias negras no espaço urbano, analisando as motivações que levaram o processo de transição de zonas rurais para os centros urbanos. A autora destaca que a partir do momento que alguns membros da família migravam para os centros urbanos, acabavam por influenciar a vinda dos demais membros da família, demonstrando o vínculo e a confiança que depositavam entre si. Na direção apontada pela historiografia brasileira recente sobre famílias de afrodescendentes no Brasil, investiga-se a seguir a trajetória dos membros da família Baptista da Silva, no pós-abolição, em Porto Alegre.

\section{Trajetórias dos membros da Família Baptista da Silva em Porto Alegre}

Vale destacar que após a abolição da escravidão e a proclamação da República, o preconceito e a discriminação racial foram obstáculos que dificultaram a integração e a mobilidade social de grande parte de afrodescendentes na sociedade brasileira. Maria Angélica Zubaran (2008) destaca que a imprensa negra, particularmente o jornal 0 Exemplo, denunciou preconceitos e discriminações raciais sofridos pela comunidade negra porto-alegrense no início do século XX, em restaurantes, praças, livrarias e cinemas da cidade.

Nesta época, segundo Sandra Pesavento (1995), a população negra estava concentrada "nos territórios negros da cidade, limitada pelo processo de exclusão que se afirmava no espaço urbano da cidade" (PESAVENTO, 1995, p. 82).

Conforme Irene Santos et al (2010), os territórios negros de Porto Alegre abrangiam o centro da cidade, os arredores da Redenção, o Quilombo do Areal da Baronesa, a Colônia Africana e Montserrat. A família Baptista da Silva morava no centro da cidade, à Rua Gen. Canabarro, no 23, no mesmo bairro em que viviam outras lideranças negras que participavam do jornal $O$ Exemplo.

O pai, João Baptista da Silva (1858-1937), nasceu em Porto Alegre, a 28 de agosto de 1858, filho de Livia Baptista e pai desconhecido. Suspeita-se que o major fosse filho de Antônio Álvaro de Araújo, que no seu inventário a ele se refere como seu afilhado e compadre 
e como padrinho do seu filho Felippe. Inferese que a paternidade não assumida por Araújo se travestiu numa relação de apadrinhamento e compadrio que gerou favorecimentos para o major João Baptista da Silva.

João Baptista da Silva casou-se com Francisca Baptista da Silva em 1880, com quem teve três filhos, Felippe Baptista da Silva, João Baptista da Silva Junior e Maria Delphina Baptista da Silva, além de Magdalena Baptista da Silva, filha de criação. Foi funcionário público da Delegacia Fiscal e ganhou notoriedade na carreira militar, tendo sido nomeado tenente da Guarda Nacional, no ano de 1893, e posteriormente recebeu o título de major, pelo qual ficou conhecido. Richard Graham (1997) sublinha o uso social da patente militar, que agregava prestígio social ao seu portador. Além desse título, Baptista da Silva foi membro do Grupo Mantenedor do jornal O Exemplo, Irmão da Santa Casa de Misericórdia de Porto Alegre, Prior da Irmandade do Rosário e Tesoureiro da Beneficência Porto-Alegrense.

João Baptista da Silva entrou para a Beneficência Porto-Alegrense, em 1886, ocupando o cargo de primeiro secretário e em 1891, quando foi eleito presidente da sociedade. 0 jornal O Exemplo destacou o papel da Beneficência Porto-Alegrense para a sociedade:

Passa amanhã o 610 aniversário da instalação da sociedade de Beneficência Porto-Alegrense. Instalada nesta capital a 25 de março de 1857 a benemérita sociedade tem atravessado esse longo período de sua existência prestando assinalados serviços a muitos dos seus numerosos associados. E seu presidente honorário o nosso velho amigo coronel Aurélio Veríssimo de Bittencourt e presidente efetivo o nosso amigo Agostinho José Lourenço. Exerce as funções de tesoureiro nosso amigo major João Baptista da Silva que é tido entre os associados da Porto -Alegrense como um forte sustentáculo daquela útil instituição e o clínico efetivo o conceituado médico operador dr. Fernando Esteves. (O EXEMPLO, 24/03/1918, p. 2)

Nesse excerto, observa-se que João Baptista da Silva é referido como "um forte sustentáculo da instituição", demonstrando sua capacidade administrativa nas questões assistencialistas, função que também desempenhou como Prior da Irmandade do Rosário.

Figura 1- João Baptista (ao centro) em frente à Igreja do Rosário.

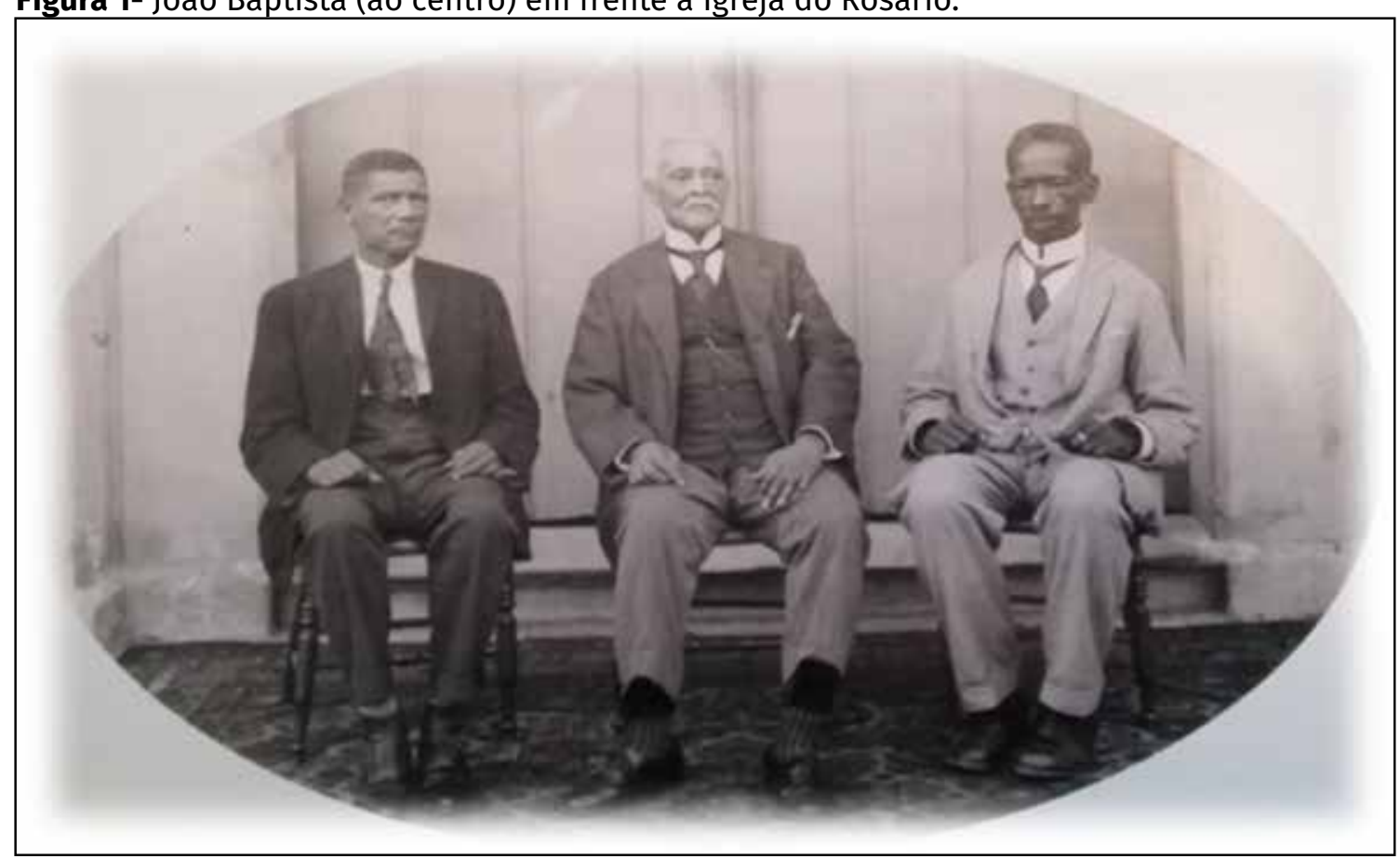

Fonte: Acervo Particular Cláudio Batista de Souza. 
Destaca-se também a participação do major João Baptista da Silva, como irmão na Santa Casa de Misericórdia de Porto Alegre. Beatriz Weber (1999), ao analisar o compromisso de irmãos da Santa Casa, no ano de 1857, destaca que a condição financeira era um dos requisitos principais para participar da associação. Weber destaca ainda que:

Os cargos da mesa administrativa foram disputados, nas várias Misericórdias brasileiras, pelo prestígio que representavam, significando prova de integridade e capacidade, rivalizando em prestígio com um cargo nas Câmaras Municipais. (WEBER, 1999, p. 139)

Além do prestígio social, ser irmão da Santa Casa representava estar apto a decidir assuntos da Mesa Administrativa que muitas vezes diziam respeito às questões da cidade.

O filho mais velho, Felippe Baptista da Silva (1883-1923) nasceu em 01 de maio de 1883 e estudou no Seminário de Pareci Novo, em S. Sebastião do Caí. Casou-se com Ercília Baptista da Silva e teve um casal de filhos, Felippe Baptista da Silva Junior e Joanna Maria de Lourdes. Sua trajetória foi semelhante à de seu pai. Entrou para a Guarda Nacional em 1909 e posteriormente, por volta de 1914, ingressou no funcionalismo público, como escriturário da Delegacia Fiscal do Tesouro Nacional, onde chegou ao posto de 40 escriturário da Alfândega. Além da formação católica no Seminário de Pareci Novo, Felippe chegou a cursar Medicina na Faculdade de Medicina Homeopática em 1914, porém abandonou o curso por razões desconhecidas. ${ }^{3}$ Entrou para o jornal $O$ Exemplo em 1917, no cargo de diretor-tesoureiro e em seguida passou a fazer parte do Grupo Mantenedor. Foi membro de várias associações de caráter religioso, escrivão da Confra-

3 Uma das possíveis razões foi o fato da Faculdade de Medicina Homeopática, recém-criada no ano de 1914, ter sido desmembrada em outras duas instituições: a Faculdade de Ciências Médicas e a Escola Médico-Cirúrgica. ria Imaculada Nossa Senhora da Conceição, primeiro secretário da Igreja Nossa Senhora das Dores, segundo secretário da Irmandade do Rosário, participou da Irmandade do Divino Espírito Santo e da Devoção de São Francisco Xavier e membro da Sociedade Centro Porto Alegrense. $^{4}$

O filho mais novo, João Baptista da Silva Junior (1891-1920), ou Baptista Junior, como ficou conhecido entre os colegas de redação do jornal 0 Exemplo, nasceu em 28 de setembro de 1891, formou-se no Ginásio Anchieta e ingressou no ensino superior, no Curso de Direito, que cursou somente até o quarto semestre, em razão do seu falecimento prematuro em 28 de outubro de 1920, vítima de pneumonia. Destacou-se no meio jurídico, nas audiências no Tribunal de Justiça e do Foro Judicial. João Baptista da Silva Junior frequentou a Faculdade de Direito e embora não tenha conseguido se formar em virtude de seu falecimento, atuou como advogado, conforme demonstra sua carteira de identidade e matérias do jornal $O$ Exemplo. Em seu obituário, o jornal $O$ Exemplo noticiava alguns casos defendidos por Baptista Junior:

Recordamo-nos apenas de que conseguiu a absolvição de um sargento da Brigada Militar, em conselho de guerra a que fora submetido naquela corporação: defendeu e conseguiu a absolvição no Tribunal do Júri, em fevereiro deste ano de Epifânio Américo dos Santos, acusado de crime de morte e finalmente, em agosto último, ainda perante o Tribunal do Júri, conseguiu a absolvição de Leopoldina Krall, acusada do crime de infanticídio. (O EXEMPLO, 31/10/1920, p. 2)

Nos autos dos referidos processos, João

4 Sociedade instrutiva e recreativa que tinha por fim desenvolver entre seus associados o gosto pelas letras, organizando uma biblioteca e promovendo palestras literárias e também proporcionar às famílias dos sócios diversões como saraus, piqueniques. Diretoria: Presidente Marcílio Francisco da Costa Freitas, Vice: Alfredo Antunes, 10 Secretário: Felippe Baptista da Silva. (A Federação, 17/02/1907, p. 2) 
Baptista da Silva Junior aparece como advogado de ambos os réus. No caso de Leopoldina Krall, além de advogado foi nomeado tutor, já que a ré era menor. Observa-se que conseguiu a absolvição da jovem em agosto de 1920. Cerca de dois meses depois Baptista Junior faleceria com 29 anos.
Em 28 de janeiro de 1917, assumiu o cargo de diretor do jornal 0 Exemplo, posto em que permaneceu até o seu falecimento. Seguem fotogravuras de membros de famílias afrodescendentes relacionadas ao jornal O Exemplo. Seguem, ainda, as fotografias dos três membros da família Baptista da Silva.
Figura 2 - Major Baptista da Silva.

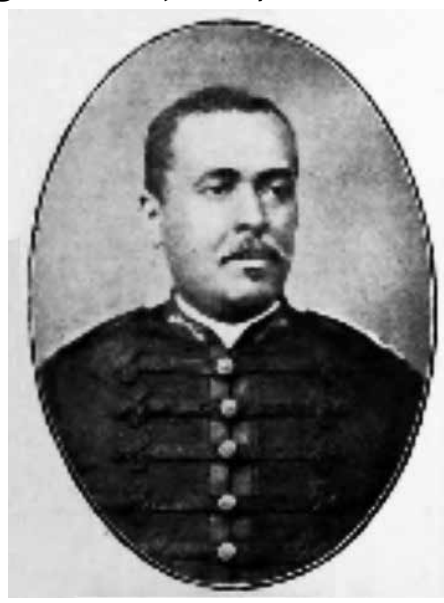

Figura 3 - Felippe Baptista.

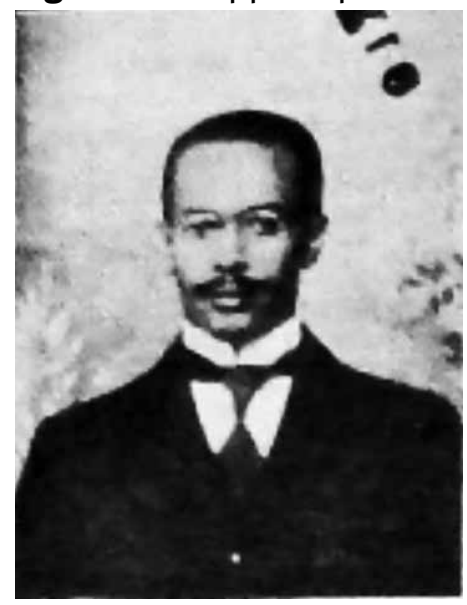

Figura 4 - João Baptista da Silva Júnior.

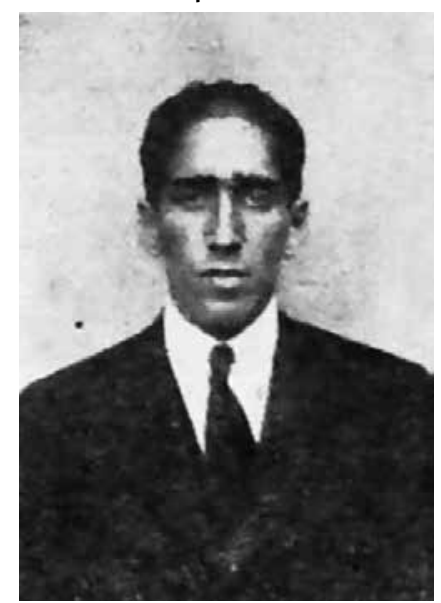

A partir do cruzamento dos fragmentos biográficos dos membros da família Baptista da Silva encontrados nos jornais O Exemplo e
A Federação e dos dados dos livros de Óbitos da Santa Casa de Misericórdia de Porto Alegre, construiu-se a seguinte tabela:

Tabela 1 - Dados sobre a Família Baptista da Silva

\begin{tabular}{|c|c|c|c|c|c|c|c|}
\hline NOME & $\begin{array}{c}\text { CONTRIBUIÇÃO } \\
\text { NO JORNAL O } \\
\text { EXEMPLO }\end{array}$ & OCUPAÇÃO & $\begin{array}{c}\text { DATA DO } \\
\text { FALECIMENTO }\end{array}$ & $\begin{array}{l}\text { IDADE AO } \\
\text { FALECER }\end{array}$ & $\begin{array}{c}\text { CAUSA } \\
\text { MORTIS* }\end{array}$ & ENDEREÇO & COR* \\
\hline $\begin{array}{l}\text { Major João } \\
\text { Baptista da } \\
\quad \text { Silva }\end{array}$ & $\begin{array}{c}\text { Membro } \\
\text { do Grupo } \\
\text { Mantenedor } \\
1920-1930\end{array}$ & $\begin{array}{c}\text { Funcionário } \\
\text { Federal do } \\
\text { Tesouro }\end{array}$ & $10 / 01 / 1937$ & 79 anos & $\begin{array}{l}\text { Insuficiência } \\
\text { cardiorrenal }\end{array}$ & $\begin{array}{c}\text { Rua Gen. } \\
\text { Canabarro, } \\
\text { no } 23\end{array}$ & Branca \\
\hline $\begin{array}{c}\text { João } \\
\text { Batista } \\
\text { da Silva } \\
\text { Júnior }\end{array}$ & $\begin{array}{c}\text { Diretor } \\
1917-1920\end{array}$ & $\begin{array}{c}\text { Funcionário } \\
\text { Federal do } \\
\text { Foro }\end{array}$ & $29 / 10 / 1920$ & 29 anos & Septicemia & $\begin{array}{c}\text { Rua Gen. } \\
\text { Canabarro, } \\
\text { nº 23, } \\
\text { Centro }\end{array}$ & Branca \\
\hline $\begin{array}{c}\text { Felippe } \\
\text { Baptista da } \\
\text { Silva }\end{array}$ & $\begin{array}{c}\text { Tesoureiro do } \\
\text { jornal } \\
1918-1923\end{array}$ & $\begin{array}{c}\text { Funcionário } \\
\text { Federal do } \\
\text { Tesouro }\end{array}$ & $05 / 08 / 1923$ & 40 anos & Pneumonia & $\begin{array}{c}\text { Rua Gen. } \\
\text { Canabarro, } \\
\text { no 23, } \\
\text { Centro }\end{array}$ & Mista \\
\hline
\end{tabular}

Fonte: Coleção do jornal O Exemplo, 1920-1930, Instituto Histórico e Geográfico do Rio Grande do Sul.

* Fonte: Livros de Óbitos da Santa Casa de Misericórdia de Porto Alegre. 
Estes fragmentos biográficos revelaram uma complexidade de sujeitos negros no contexto do pós-abolição e a importância do emprego público federal para o estabelecimento de uma classe média negra em Porto Alegre, cuja inserção social foi também facilitada pelas patentes militares e a participação em sociedades religiosas e recreativas.

Por outro lado, quando se compara as fotografias dos membros da família Baptista da Silva com o registro da cor nos Livros de Óbitos da Santa Casa, observa-se uma tendência a um "embranquecimento" desses afrodescendentes, nos registros oficiais. De acordo com Lilia Schwarcz, as negociações em torno da cor estavam relacionadas à situação socioeconômica e cultural dos indivíduos. Enriquecer, ter educação superior, frequentar locais sociais de estrato mais alto, tudo levava a um certo "embranquecimento" (SCHWARCZ, 2012, p. 106). A cor branca atribuída aos membros da família Baptista da Silva nestes documentos oficiais pode ser lida também como um atributo necessário para quem ocupava um lugar social de destaque, para o qual uma certa aparência de branquitude era exigida. Conforme Liv Sovik (2009), "Ser mais ou menos branco não dependia simplesmente da genética, mas do estatuto social".

Os fragmentos biográficos da família de afrodescendentes Baptista da Silva evidenciam a participação ativa destes sujeitos em redes sociais e culturais diversas, na sociedade porto-alegrense, contrariando estereótipos racistas que se agudizavam no pós-abolição. Neste sentido, pode-se afirmar que o major Baptista da Silva e seus filhos Felippe e Baptista Junior participaram da modernização cultural e urbana de Porto Alegre, não como coadjuvantes, mas como protagonistas, destacando-se nos espaços sociais em que estavam inseridos.

\section{Considerações Finais}

Neste estudo pretendeu-se analisar memórias e trajetórias de uma família negra no pós-abolição em Porto Alegre. A análise da família em questão contribuiu para complexificar os estudos sobre a formação da família negra no final do século XIX e primeiras décadas do século $X X$, demonstrando como refere Benito $B$. Schmidt "que por mais eficientes que sejam as políticas de domínio, existem sempre margens de manobra, opções de escolhas" (2013, p. 69-70). Neste caso, a pesquisa revelou múltiplas redes sociais tecidas, construídas pelos membros de uma família negra no pós-abolição em Porto Alegre e o protagonismo de seus membros, superando as barreiras do racismo e obtendo reconhecimento na sociedade porto-alegrense da época.

A análise realizada demonstrou que os laços de compadrio foram parte da ascensão social da família Baptista da Silva na sociedade brasileira daquela época. Seu provável pai não assumiu a paternidade do filho da sua escrava, mas the manifestou apoio ao longo da sua vida. Também chama a atenção, o envolvimento dos diferentes membros da família Baptista da Silva com associações religiosas, como a Irmandade de N. S. do Rosário, a Igreja de N. S. das Dores, a Irmandade de N. S. da Conceição. Destaca-se particularmente a trajetória do major como Prior da Irmandade do Rosário, realizando atividades de cunho assistencialista, também em outras instituições, como na Santa Casa de Misericórdia e na Beneficência Porto-Alegrense. As Irmandades religiosas foram também fundamentais na ascensão social de afrodescendentes no pós-abolição.

Uma terceira questão a ser destacada na trajetória desta família foi o investimento na educação como mecanismo de ascensão social e de superação do racismo. Tanto Felippe Baptista da Silva, como seu irmão Baptista Junior 
frequentaram cursos superiores. 0 primeiro ingressou na Faculdade de Medicina Homeopática em Porto Alegre, embora não tenha completado o curso. O segundo cursou a Faculdade de Direito em Porto Alegre e apesar de não ter recebido o diploma, atuava nessa área mesmo antes de se graduar.

Por último, vale salientar a importância dessa família na imprensa negra de Porto Alegre, mais especificamente, no jornal $O$ Exemplo, onde o major fazia parte do Grupo mantenedor do jornal, Felippe desempenhou a função de tesoureiro e Baptista Junior ocupou o cargo de diretor do jornal.

Algumas questões merecem estudos mais aprofundados, tais como a relevância da carreira militar na trajetória de afrodescendentes no pós-abolição, assim como a importância do associativismo negro, particularmente a participação de afrodescendentes em irmandades negras. Ficou também evidente o silêncio sobre a trajetória das mulheres nas famílias negras. Tais questões apontam para a necessidade de novas pesquisas sobre a pluralidade das experiências de famílias negras no pós-abolição e, particularmente, para reflexões sobre o papel das mulheres negras, que foram silenciadas nas narrativas do jornal $O$ Exemplo, mas que foram fundamentais para manter as famílias negras no pós-abolição. Suas trajetórias remetem à resistência de mulheres negras desde os quilombos coloniais, à participação em rebeliões escravas, como lideranças e mães de terreiro, até às múltiplas estratégias de sobrevivência no mercado urbano, como quitandeiras nas praças e mercados. Assim, se a mãe do major Baptista, Lívia Baptista e a filha, Maria Delphina, ficaram silenciadas nas narrativas do jornal $O$ Exemplo, não significa que suas experiências e trajetórias foram menos importantes que a dos membros masculinos da família, mas aponta para as limitações de raça e de gênero da sociedade rio-grandense daquela época. Na verdade, foram as memórias orais da filha Delphina que possibilitaram a reconstituição da história dessa família nas gerações que the sucederam.

Pode-se concluir, portanto, que a imprensa negra alternativa contribuiu para que a presença de uma classe média negra letrada e com múltiplos vínculos sociais, em diferentes esferas e espaços da sociedade porto-alegrense, fosse visibilizada, com exceção para o papel das mulheres negras, que foi esquecido e negligenciado. Tais considerações também colocam em discussão ideias simplistas sobre famílias negras anômicas e marginalizadas culturalmente, social e politicamente. Como foi observado, apesar das inúmeras dificuldades e tensões raciais da sociedade brasileira e rio-grandense, o protagonismo de sujeitos negros contribuiu para a superação de barreiras sociais e raciais e para a construção de identidades negras múltiplas e afirmativas no pós-abolição no Rio Grande do Sul.

\section{Referências}

DOMINGUES, Petrônio. Fios de Ariadne, o protagonismo negro no pós-abolição. Anos 90, Porto Alegre, v. 16, n. 30, p. 215-250, dez. 2009.

DOSSE, François. A Biografia, Gênero Impuro. In: O desafio biográfico - Escrever uma vida. Tradução de Gilson César C. Souza. São Paulo: Editora da Universidade de São Paulo, 2009. p. 55-99.

FARIA, Sheila de Castro. A colônia em movimento. Rio de Janeiro: Nova Fronteira, 1998.

FLORENTINO, Manolo; GÓES, José Roberto. A paz das senzalas: famílias escravas e tráfico atlântico, Rio de Janeiro, 1790-1850. Civilização Brasileira: Rio de Janeiro, 1997.

GODOI, Rodrigo Camargo de. Um editor no Império: Francisco de Paula Brito (1809-1861). São Paulo: Editora da USP; FAPESP, 2016.

GOMES, Fabrício Romani. Sob a proteção da Prince- 
sa e de São Benedito: identidade étnica, associativismo e projetos num clube negro de Caxias do Sul (1934-1988). 2008. 219 f. Dissertação (Mestrado em História) - Universidade do Vale do Rio dos Sinos, São Leopoldo, 2008.

GOMES, Flávio. (Org). Políticas da abolição e da pós-emancipação no Brasil. São Paulo: Selo Negro, 2014. p. 231-261.

GRAHAM, Richard. A Estruturas da Política: Família, Clientes e Controle Social. In: Clientelismo e política no Brasil do século XIX. Rio de Janeiro: Editora UFRJ, 1997. p. 27-66.

JESUS, Gilmar Mascarenhas de. O futebol da canela preta: o negro e a modernidade em Porto Alegre. Anos 90, Porto Alegre, n. 11, p. 144-161, jul. 1999.

LUNA, Francisco Vidal; KLEIN, Herbert S. Escravismo no Brasil. São Paulo: EDUSP, 2010.

LAUREANO, Marisa. O papel da família escrava no Rio Grande do Sul colonial: 1737-1800. In: MAESTRI, Mario; AMARO, Luiz Carlos. (Orgs.). Afro-brasileiros: história e realidade. Porto Alegre: EST, 2005. v. 5. p. 114-122.

LORIGA, Sabina. O limiar biográfico. In: 0 pequeno x: da biografia à história. Tradução de Fernando Scheibe. Belo Horizonte: Autêntica, 2011. p. $17-48$

LONER, Beatriz Ana. Trajetórias de "setores médios" no pós-emancipação: Justo, Serafim e Juvenal. In: Encontro Escravidão e Liberdade no Brasil Meridional (5.: 2011: Porto Alegre, RS).

MATTOS, Hebe Maria. Laços de família. In:

Das cores do silêncio: os significados da liberdade no Sudeste escravista, Brasil século XIX. Rio de Janeiro: Nova Fronteira, 1998. p. 55-73

MIRANDA, Terence Burchert. Mobilidade e trabalho: trajetórias de famílias negras de Biguaçu na primeira metade do século XX. 2013118 f. Monografia (Graduação em História) - Centro de Filosofia e Ciências Humanas, Universidade Federal de Santa Catarina, Florianópolis, 2013.

MOREIRA, Paulo Roberto Staudt. Aurélio Viríssimo de Bittencourt: Burocracia, Política e Devoção. In: DOMINGUES, Petrônio; GOMES; Flávio. (Orgs). Expe- riências da emancipação: biografias, instituições e movimentos sociais no pós-abolição (1890-1980). São Paulo: Selo Negro, 2011. p. 83-107.

MÜLLER, Liane Susan. As contas do meu Rosário são balas de artilharia. Porto Alegre: Pragmatha, 2013.

PERES, Eliane. Sob(re) o silêncio das fontes... A trajetória de uma pesquisa em história da educação e o tratamento das questões étnico-raciais. Revista Brasileira de História da Educação, n. 4, p. 75-102, jul./dez. 2002.

PESAVENTO, Sandra Jlatahy. Os excluídos da cidade. In: SEFFNER, Fernando. Presença negra no Rio Grande do Sul. Porto Alegre: Cadernos Ponto \& Vírgula, 1995. p. 81-89.

RIOS, Ana Maria Lugão. Família e transição: famílias negras em Paraíba do Sul 1872-1920. Revista Bras. Estudos Pop, Campinas, v. 7, n. 2, p. 243-247, 1990.

ROSO, Adriane. Psicologia e história: acerca da construção de árvores genealógicas ou como retomar lembranças de família em sociedades de rede. PSICO, v. 41, n. 3, p. 385-92, jul./set. 2010.

SALLES, Ricardo; SOARES, Mariza de Carvalho. Episódios de história afro-brasileira. Rio de Janeiro: DP\&A; Fase, 2005.

SANTOS, José Antônio dos. O Curriculum Vitae como vestígio do passado. Dario de Bittencourt (1901-1974): uma eminência duplamente parda. In: ENCONTRO ESTADUAL DE HISTÓRIA, 9., 2008, Porto Alegre. Vestígios do passado: a história e suas fontes, Anais eletrônicos. Porto Alegre: Associação Nacional de História - ANPUH-RS, 2008. p. 1-12.

Prisioneiros da história: trajetórias intelectuais na imprensa negra meridional. 2011. 281f. Tese (Doutorado em História) - Faculdade de Filosofia e Ciências Humanas, Pontifícia Universidade Católica do Rio Grande do Sul, Porto Alegre, 2011.

SANTOS, Irene; SILVA, Cidinha da.; FIALHO, Dorvalina E. P.; BARCELLOS, Vera Daisy; BETTIOL, Zoravia. (Orgs.). Colonos e quilombolas: memória fotográfica das colônias africanas de Porto Alegre. Porto Alegre: [s/n], 2010. 
SCHMIDT, Benito Bisso. Que diferença faz? Os estudos biográficos na história do trabalho brasileira. In: FORTES, Alexandre et al. (Org.). Cruzando fronteiras: novos olhares sobre a história do trabalho. São Paulo: Editora Fundação Perseu Abramo, 2013. p. 61-76.

. Um socialista no Rio Grande do Sul: Antonio Guedes Coutinho (1868-1945). Porto Alegre: Editora da UFRGS, 2000.

SCHWARCZ, Lilia M. Nem preto, nem braço, muito pelo contrário: cor e raça na sociabilidade brasileira. São Paulo: Claro Enigma, 2012.

SLENES, Robert Wayne. Lares negros, olhares brancos. In: Na senzala, uma flor - esperanças e recordações na formação da família escrava: Brasil Sudeste, século XIX. Rio de Janeiro: Nova Fronteira, 1999. p. 134-42.

SOVIK, Liv. Aqui ninguém é branco. Rio de Janeiro: Aeroplano, 2009.

VELHO, Keter. Teu amigo certo: Júlio de Castilhos correspondência inédita. Porto Alegre: Edijuc, 2013.

WEBER, Beatriz Teixeira. Artes de curar: medicina, religião, magia e positivismo na República RioGrandense (1889-1928). Santa Maria: Editora da UFSM; Bauru: EDUSC, 1999. p. 134-163.
WEIMER, Rodrigo de Azevedo. A gente de Felisberta. Consciência histórica, história e memória de uma família negra no litoral rio-grandense no pós-emancipação (c. 1847 - tempo presente). 2013. 467 f. Tese (Doutorado em História) - Instituto de Ciências Humanas e Filosofia, Universidade Federal Fluminense, Niterói, 2013.

ZUBARAN, Maria Angélica. Comemorações da liberdade: lugares de memórias negras diaspóricas.

Anos 90, Porto Alegre, p. 161-187, jul. 2008.

ZUBARAN, Maria Angélica. História, acervo e protagonismo negro no jornal O Exemplo (1892-1930). In: SILVA, Fernanda Oliveira da.; PERUSSATO, Melina Kleinert; WEIMER, Rodrigo de Azevedo; SILVA, Sarah Calvi Amaral. Ciclo de debates sobre o jornal $O$ Exemplo, Porto Alegre (versão e-book). Instituto Histórico e Geográfico do Rio Grande do Sul, 2016. p. 7-19.

\section{Fontes}

Jornal $O$ Exemplo, 24 de março de 1918, p.2. Jornal $O$ Exemplo, 31 de outubro de 1920, p.2. Jornal A Federação, 17 de fevereiro de 1907, p. 2.

Recebido em: 28.02.2018

Aprovado em: 19.08.2018

Maria Angélica Zubaran é Professora Adjunta do Curso de História e do Mestrado e Doutorado em Educação da Universidade Luterana do Brasil. Doutora em História na State University of New York, em Stony Brook e Pós-Doutora no Birkbeck College da London University. e-mail: angelicazubaran@yahoo.com.br

Estácio de Sá, 151, Porto Alegre, 91330-430. Telefone (051) 34075805

Vitor da Silva Costa é Bacharel em História pela Universidade Luterana do Brasil e Mestrando em História na Universidade do Vale do Rio dos Sinos. e-mail:vcosta046@gmail.com

Rua Rio Branco, 2485, Taquara, 95600-518 Telefone: (051) 97990199. 